\title{
Phylogenetic Analysis of Alternaria species Associated with Citrus Black Rot in Iran
}

Shideh Mojerlou and Naser Safaie*

Department of Plant Pathology, College of Agriculture, Tarbiat Modares University, Tehran, Iran

\begin{abstract}
Citrus black rot caused by Alternaria spp. is significant post harvest problem in Iran. The causal agent of black rot was originally identified as $A$. citri by Ellis and Pierce. The genus Alternaria circumscribes considerable morphological diversity and citrus black rot may be caused by more than one morphospecies in addition to $A$. citri. Morphological identification of small-spored Alternaria spp. is difficult. Phylogenetic analysis was performed on 7 small-spored Alternaria isolates from black rotted citrus fruit in Iran using sequence data from an anonymous locus, OPA10-2. Samples were collected from navel oranges in Mazandaran province in the north of Iran. All isolates caused black rot in a fruit inoculation assay with Navel and Valencia oranges and significant differences were observed between cultivars and among isolates. No association was found between morphological classification and phylogenetic clade. We identified $A$. tenuissima (ALT 6) as the causal agents of citrus black rot. Two isolates (ALT8 and ALT9) grouped together, separately from other clades in most parsimonious trees. It suggested that both of them belong to different species. This is the first report of molecular characterization of citrus-associated Alternaria species in Iran and $A$. tenuissima is reported as the causal agent of citrus black rot in Iran for the first time.
\end{abstract}

Keywords: Citrus; Alternaria spp.; Black rot; Phylogenetic analysis; Anonymous locus

\section{Introduction}

Citrus black rot is a well known post harvest disease which produces internal decay of citrus fruit. The disease is caused by several small-spored Alternaria species [1-4]. Alternaria species cause other diseases of citrus including, brown spot of tangerine, leaf and fruit spot of rough lemon and Rangpur lime, and Mancha foliar de los citricos affecting Mexican lime [2,5].

Alternaria black rot of citrus may occur in the field before harvest. It infected most commonly citrus, navel oranges (Citrus sinensis (L.) Osbeck) in the field and their hybrids in the storage. The pathogen can infect all citrus fruits under suitable condition $[2,6]$. The disease is a common problem in Mediterranean climates due to cool, moist winters and hot dry summers [7]. Black rot isolates do not require host specific toxins for pathogenicity $[1,5]$. Wounds or natural opening in the stylar facilitate the infection process. Alternaria spp. may induce dormant infections on calyx and disk and invade the columella of matured fruits resulting in black rot $[2,6,8]$.

The causal agent of black rot was first described in early 1900s as Alternaria citri by Ellis \& Pierce $[2,9,10]$. However, other species of Alternaria may cause citrus black rot, too [11-13]. Historically the causal agent of black rot, brown spot of tangerine and leaf spot of rough lemon named as $A$. citri just for their association with Citrus spp. hosts [6,7,14-16]. But morphological identification or DNA analysis was not used to identify these fungi. 10 morphological species were described within brown spot and rough lemon leaf spot isolates which collected worldwide [2,17]. Peever et al. [18] revealed that many of the morphospecies which described by Simons $[4,17]$ were both paraphyletic and polyphyletic. Peever et al. [18] studied citrusassociated species of Alternaria using mitochondrial large subunit (mtLSU) and $\beta$-tubulin sequence data. All small and catenulatespored species formed monophyletic lineage. This lineage included causal agent of brown spot of tangerine, leaf spot of rough lemon and saprophytic isolates associated with citrus and other plants.
Peever et al. [2] showed that phylogenetically distinct lineage of $A$. alternata is caused citrus black rot. Citrus associated isolates included isolates which cause brown spot of tangerine and their hybrids, leaf spot of rough lemon, isolate of healthy citrus leaf tissue and black rotted fruit were assigned in eight clades in a combined endo-PG, OPA1-3 and OPA1-2 phylogeny [2]. Isolates which collected from black rotted fruit were distributed in six combined clades clustered with isolates which collected from other ecological niches on citrus and other plant host including peanut, tomato and carnation. These isolates were able to cause black rot, too [2].

Rang et al. [12] studied morphologically the isolates of blackrotted Minneola Tangelo, Mandarin and Navel Orange in South Africa. They assigned the isolates to the A. alternata, A. pellucida, A. citri, A. tenuissima and A. arborescens morphospecies. They used ITS and histone 3 sequences for phylogenetic analysis. The isolates divided to four clades. Researchers [19-22] concluded the isolates which cause brown spot of tangerine and leaf spot of rough lemon were morphologically identical and conspecific with causal agent of black rot [2]. These comparisons were based on morphological data which were insufficient for taxonomic differentiation of small-spored Alternaria $[13,17]$. Peever et al. [2] showed that $A$. citri sensu Simons include paraphyletic or polyphyletic fungi.

There is no phylogenetic or pathological evidence to demonstrate that A. citri is distinct taxonomic category that causes black rot.

*Corresponding author: Naser Safaie, Department of Plant Pathology, Faculty of Agriculture, Tarbiat Modares University, PO Box 14155-336, Tehran, Iran, Tel: +98 2148292346; Fax: +98 2148292200; E-mail: nsafaie@modares.ac.ir

Received October 18, 2012; Accepted November 17, 2012; Published November 22, 2012

Citation: Mojerlou S, Safaie N (2012) Phylogenetic Analysis of Alternaria species Associated with Citrus Black Rot in Iran. J Plant Pathol Microb 3:144. doi:10.4172/2157-7471.1000144

Copyright: @ 2012 Mojerlou S, et al. This is an open-access article distributed under the terms of the Creative Commons Attribution License, which permits unrestricted use, distribution, and reproduction in any medium, provided the original author and source are credited. 
Peever et al. [18] suggested that citrus associated small-spored species should be referred to A. alternata until more genetic or physiological data achieved for their differentiation [23]. Sequence data from mitochondrial large ribosomal subunit, $\beta$-tubulin and other regions of genome such as region that encoding chitin synthase, calmodulin, actin, 1,3,8-trihydroxy naphthalene reductase unable to differentiate 10 morphological species and also unable to detect causal agent of black rot from isolates which recovered from healthy citrus tissue $[1,24]$. Only endo-polygalacturonase and two anonymous loci enable to differentiate members of the Alternata specie group [18].

There is a considerable morphological diversity in the genus Alternaria. Many researchers attempt to organize taxa to sub group based on similar morphological characters [25-27]. Simmons [13] proposed 14 morphological groups to describe morphospecies. Then molecular studies confirmed many of these groups as monophyletic and assigned as "species-group" [28-30]. Other researchers differentiate species of small-spored Alternaria using metabolic profiling, morphology of the colony on standardized media and pattern of the conidial branching [31-41].

Stewart [42] used endoPG, OPA1-3, OPA2-1 and two microsatellite flanking regions for phylogenetic analysis of citrus brown spot worldwide. Pathogenic forms of $A$. alternata appear to have radiated from a recent common saprophytic ancestor [43]. With the divergence of the citrus 2 lineage, Stewart [42] suggested that a more complex evolution history is possible. Radiation may have occurred with the brown spot pathogen, two lineages of the citrus brown spot pathogen exist. Based on the coalescent analyses and GCPSR results; lineage citrus 2 appears to be derived from citrus 1. Loci Flank-F3 and OPA1-3 revealed strong evidence for a history of recombination among lineages. Andrew et al. [23] estimated phylogenies using endoPG, OPA1-3, and OPA10-2, and showed that A. arborescens formed a monophyletic sister group to A. alternata in the OPA1-3 and 10-2 phylogenies, but not in the endoPG phylogeny. This and the putative recombination observed in evolutionary history of OPA1-3 suggest that $A$. arborescens and A. alternata are recently diverged closely-related species. For future studies, a more distant relative of A. alternata may be more appropriate as an out group [42].

Kakvan et al. [44] showed high genetic diversity of A. alternate isolates which were collected from citrus hybrids of Iran using RAPDPCR. There is no report on phylogenetic study of citrus black rot from Iran. The object of this study is phylogenetic classification of causal agent of citrus black rot in Iran and complementary studies are in progress.

\section{Materials and Methods}

\section{Isolate sampling}

Twenty single-conidial isolates of small and catenulate spored citrus-associated Alternaria spp. were isolated from citrus with symptoms of black rot from North of Iran, including, Sari, Jouybar, Ghaemshahr and Ramsar in Mazandaran province (Table 1). Also, we used some NCBI accessions for comparison (Table 1).

\section{Preparing conidial inoculation}

Single-conidial isolates were grown on Potato Carrot Agar (PCA) medium incubated at $27^{\circ} \mathrm{C}$, under 16 hours photoperiod for 3 to 5 days to promote conidial production. Conidia were collected by washing with water sterile from the plates. Conidia concentration were adjusted to $5 \times 10^{4}$ conidia/ml using haemocytometer.

\section{Pathogenicity test}

Navel and Valencia oranges were obtained from the field and disinfested with $70 \%$ ethanol. Calyces were removed from fruits before inoculation. Inoculation was performed by injecting $100 \mu \mathrm{l}$ of conidial suspension $\left(5 \times 10^{4}\right.$ conidia/ml $)$ into columella with syringe. For each isolates, six fruits were inoculated and incubated at 23 to $25^{\circ} \mathrm{C}$ for 21 days. Fruits were scored on a scale of 0 to 3 [2].

\section{Morphological assay}

Isolates were grown on PCA medium under 16 hour photoperiod at room temperature for 5-7 days. Morphological classification was performed by comparing colony morphology, sporulation branching patterns and conidial size using Simmons identification key [45].

\section{Fungal culture and DNA extraction}

Isolates were grown in PDB (Potato Dextrose Broth) medium for 5 days and incubated on shaker with $135 \mathrm{rpm}$ at $25^{\circ} \mathrm{C}$. Mycelium was collected under vacuum. DNA was extracted by Safaie et al. [46] procedure. DNA concentration was estimated visually in $0.8 \%$ agarose gel.

\section{PCR and sequencing}

An anonymous region of Alternaria genome, OPA10-2 [23], was amplified and sequenced as described by Andrew et al. [23]. An approximately 800 bp amplicon was obtained with OPA10-2 primers. Amplification products were visualized in $1.2 \%$ agarose gel. PCR products were direct sequenced. Sequencing was performed by the Kawsar Biotech Company (www.kawsar.ir).

\section{Phylogenetic analysis}

OPA10-2 sequences were aligned using Mega 4.0 software. Maximum parsimony was used in Mega 4.0 to infer the phylogeny. Support for clades was estimated using non-parametirc bootstrapping with 100 pseudo-replicated datasets in Mega. Consensus tree was produced by Mega 4.0.

\section{Results and Discussion}

\section{Isolates sampling and morphological identification}

Twenty isolates were collected from infected citrus fruit (Figure 1A) and studied morphologically using Simmons' [45] identification key. Seven isolates were selected for phylogenetic analysis (Table 1).

Isolates were cultured on PCA medium and incubated under 16 hours photoperiod at room temperature for 5-7 days (Figure 1B).

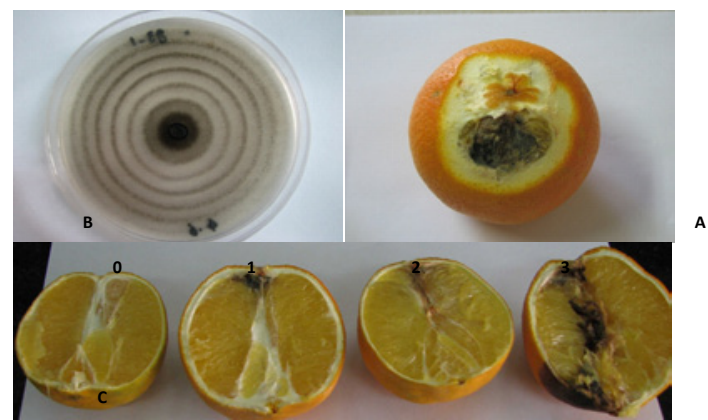

Figure 1: Symptom of black rot on citrus fruit (A), Alternaria spp. colony on PCA medium after 5-7 days (B), pathogenicity assessment scale of Alternaria spp. on inoculated fruit (C). 
Citation: Mojerlou S, Safaie N (2012) Phylogenetic Analysis of Alternaria species Associated with Citrus Black Rot in Iran. J Plant Pathol Microb 3:144. doi:10.4172/2157-7471.1000144

\begin{tabular}{|l|l|l|}
\hline Name & Host & Location \\
\hline Alt 2 & Orange & Sari \\
\hline Alt 4 & Orange & Sari \\
\hline Alt 6 & Orange & Ghaemshahr \\
\hline Alt 8 & Orange & Ghaemshahr \\
\hline Alt 9 & Orange & Jouybar \\
\hline Alt 10 & Orange & Sari \\
\hline Alt 20 & Kiwi fruit & Ramsar \\
\hline gi- 154433690 & - & Andrew et al. [23] \\
\hline gi- 154433692 & - & Andrew et al. [23] \\
\hline gi- 154433695 & - & Andrew et al. [23] \\
\hline gi- 154433697 & - & Andrew et al. [23] \\
\hline gi- 154433698 & - & Andrew et al. [23] \\
\hline gi- 154433700 & - & Andrew et al. [23] \\
\hline gi- 154433701 & - & Andrew et al. [23] \\
\hline gi- 154433745 & - & Andrew et al. [23] \\
\hline gi- 154433886 & - & Andrew et al. [23] \\
\hline
\end{tabular}

Table 1: List of Alternaria spp. isolates used for phylogenetic analysis.
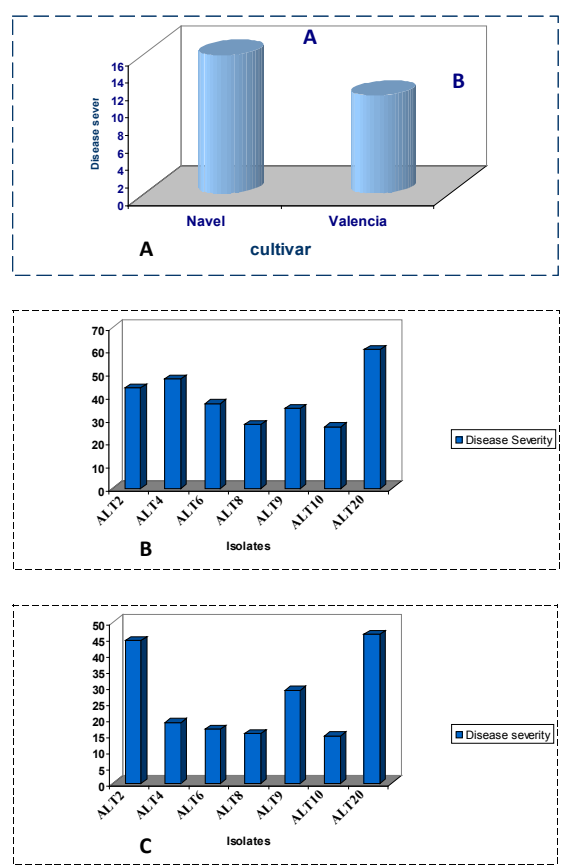

Figure 2: Disease severity of Navel and Valencia cultivars interact with Alternaria spp. (A), Disease severity of Navel cultivar interact with Alternaria spp. isolates (B), Disease severity of Valencia cultivar interact with Alternaria spp. isolates $(\mathrm{C})$.

Morphological characters including colony morphology, conidial size and branching patterns could not separate species. Our result corresponding to other researchers, that few morphological characters can differentiate small spored species within Alternaria species-group $[18,23]$.

\section{Pathogenicity test}

Seven isolates from black-rotted fruit were inoculated to Navel and Valencia cultivars in order to test pathogenicity. Twenty-one days post-inoculation disease severity was recorded according to 0 to 3 scale described by Peever et al. [2]. Significant differences in mean disease rating were observed between cultivars (Figure 2). Disease severity was higher on Navel compared to Valencia. However, no significant isolate by cultivar interaction was observed. ANOVA of cultivar-isolate interactions and different isolates and cultivars are shown in table 2.

Our results agree with those of Brown and Eckert [7]. Isolates Alt20 and Alt10 had highest and lowest disease severity on Navel (26.58 and $60.14 \%$ ) and Valencia (14.61 and $46.02 \%$ ), respectively.

\section{Phylogenetic analysis}

Approximately $800 \mathrm{bp}$ of an anonymous, non-coding region was sequenced for 7 isolates from black-rotted fruit in Iran. Sequenced data were analyzed by Mega 4.0 software and a consensus tree estimated. The consensus trees estimated for OPA10-2 locus was showed at figure 3.

Morphological characters were not a reliable predictor of phylogenetic lineage, a result similar to that observed by Andrew et al. [23]. No association was found between morphological and phylogenetic data. We identified A. tenuissima as the causal agent of citrus black rot. A tenuissima introduce for the first time as causal agent of citrus black rot from Iran.

The results showed that (Figure 3), ALT2, ALT4 and ALT10 grouped with $A$. gaisen and A. limoniasperae but they were not supported well and were non stable in different trees. Also, ALT20 placed in the clade of $A$. citrimacularis and A. citriarbusti. Its situation was changed in different trees. ALT6 was designated as A. tenuissima in the most parsimonious trees. The isolates ALT8 and ALT9 grouped together, separately from other clades in most parsimonious trees. It suggested that both of them belong to different species.

Morphological distinguish within small-spored Alternaria species is a taxonomic problem and Rapid identification need to determine species name. Meanwhile, molecular and morphological characters should be considered together [23]. Phylogenetic classification of small-spored Alternaria species associated with citrus black rot in Iran

\begin{tabular}{|l|l|l|l|l|}
\hline Source & $\begin{array}{l}\text { Degrees of } \\
\text { Freedom }\end{array}$ & $\begin{array}{l}\text { Sum of } \\
\text { Squares }\end{array}$ & $\begin{array}{l}\text { Mean } \\
\text { Squares }\end{array}$ & F Value \\
\hline Isolate & 1 & 0.082 & 0.082 & $4.9631^{*}$ \\
\hline Cultivar & 6 & 0.206 & 0.034 & 2.08 \\
\hline Cultivar-Isolate & 6 & 0.030 & 0.005 & 0.30 \\
\hline Error & 70 & 1.153 & 0.016 & \\
\hline Total & $\mathbf{8 3}$ & $\mathbf{1 . 4 7 1}$ & & \\
\hline
\end{tabular}

${ }^{*} \mathrm{P} \leq 0.05$, Coefficient of variation $=14.57 \%$

Table 2: ANOVA of disease severity in cultivars (Navel and Valencia) interact with seven genotypes of Alternaria spp.

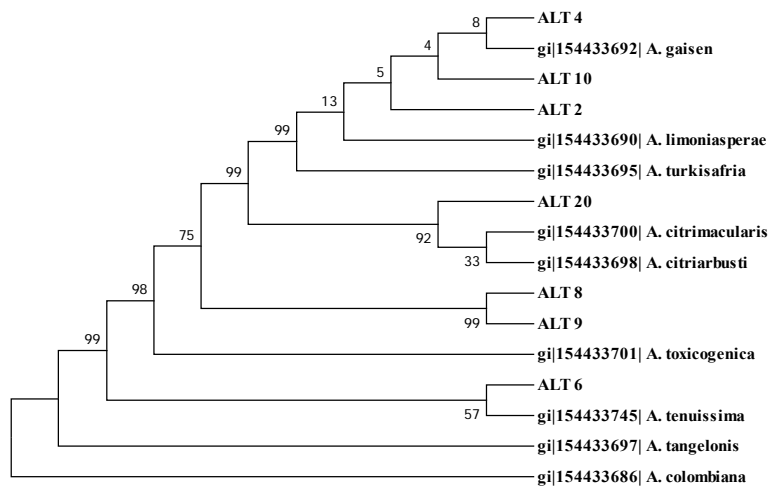

Figure 3: Consensus tree of OPA10-2 locus by Maximum Parsimony method using MEGA4.0 software. 
Citation: Mojerlou S, Safaie N (2012) Phylogenetic Analysis of Alternaria species Associated with Citrus Black Rot in Iran. J Plant Pathol Microb 3:144. doi:10.4172/2157-7471.1000144

needs to complementary studies with more isolates and more sequence data from other genome loci.

\section{Acknowledgment}

The authors deeply thank Dr. Tobin Peever from the Department of Plant Pathology, Washington State University, for helpful suggestions and answering numerous questions. We also thank M.Sc. Hossein Taheri for sending isolate from Iran Citrus Research Institute (RAMSAR)

\section{References}

1. Akimitsu K, Peever TL, Timmer LW (2003) Molecular, ecological and evolutionary approaches to understanding Alternaria diseases of citrus. Mol Plant Pathol 4: 435-446.

2. Peever TL, Carpenter-Boggs L, Timmer LW, Carris LM, Bhatia A (2005) Citrus black rot is caused by phylogenetically distinct lineages of Alternaria alternata. Phytopathology 95: 512-518.

3. Serdani M, Kang JC, Andersen B, Crous PW (2002) Characterisation of Alternaria species-groups associated with core rot of apples in South Africa. Mycol Res 106: 561-569.

4. Simmons EG (1999) Alternaria themes and variations (226-235): classification of citrus pathogens. Mycotaxon 70: 263-323.

5. Timmer LW, Peever TL, Solel Z, Akimitsu K (2003) Alternaria diseases of citrusnovel pathosystems. Phytopathol Mediterr 42: 99-112.

6. Brown GE, McCornack AA (1972) Decay caused by Alternaria citri in Florida citrus fruit. Plant Dis Rep 56: 909-912.

7. Brown GE, Eckert JW (2000) Alternaria rot. Page 37 in: Compendium of Citrus Diseases. LW Timmer, S M Garnsey, and JH Graham, eds. The American Phytopathological Society, St. Paul, MN.

8. Schiffmann-Nadel M, Waks J, Gutter Y, Chalutz E (1981) Alternaria rot of citrus fruit. Proc Int Soc Citricult 2: 791-793.

9. Cobb NA (1903) Letters on the diseases of plants-Alternaria of the citrus tribe Agric Gaz N S W 14: 955-986

10. Pierce NB (1902) Black rot of oranges. Bot Gaz 33: 234-235.

11. Doidge EM, Bottomley AM, van der Plank JE, Pauer GD (1953) A revised list of plant diseases in South Africa. S Afr Dep Agric Sci Bull 346: 1-122.

12. Rang JC, Crous PW, Mchau GRA, Serdani M, Song SM (2002) Phylogenetic analysis of Alternaria spp. associated with apple core rot and citrus black rot in South Africa. Mycol Res 106: 1151-1162.

13. Simmons EG (1992) Alternaria taxonomy: Current status, viewpoint, challenge In: Chelkowski J, Visconti A, eds. Alternaria: biology, plant diseases and metabolites, Elsevier Science Publishers, New York 1-36.

14. Cotty PJ, Misaghi IJ (1984) Zinniol production by Alternaria species Phytopathology 74: 785-788.

15. Isshiki A, Akimitsu K, Yamamoto M, Yamamoto H (2001) Endopolygalacturonase is essential for citrus black rot caused by Alternaria citri but not brown spot caused by Alternaria alternata. Mol Plant Microbe Interact 14: 749-757.

16. Kohmoto K, Scheffer RP, Whiteside JO (1979) Host-selective toxins from Alternaria citri. Phytopathology 69: 667-671.

17. Simmons EG (1999) Alternaria themes and variations (236-243): host-specific toxin producers. Mycotaxon 70: 325-369.

18. Peever TL, Su G, Carpenter-Boggs L, Timmer LW (2004) Molecular systematics of citrus-associated Alternaria species. Mycologia 96: 119-134.

19. Doidge EM (1929) A study of some Alternarias infecting citrus in South Africa Union S Afr Dep Agric Sci Bull 69: 1-29

20. Ruehle GD (1937) A strain of Alternaria citri Ellis and Pierce causing a leaf spo of rough lemon in Florida. Phytopathology 27: 863-865.

21. Kiely TB (1964) Brown spot of Emperor mandarin. Agric Gaz NSW 75: 854-856.

22. Pegg KG (1966) Studies of a strain of Alternaria citri Pierce, the causa organism of brown spot of Emperor mandarin. Qld J Agric Anim Sci 23: 15-28.

23. Andrew M, Peever TL, Pryor BM (2009) An expanded multilocus phylogeny does not resolve morphological species within the small-spored Altemrnaria species complex. Mycologia 101: 95-109.
24. Peever TL, Ibanez A, Akimitsu K, Timmer LW (2002) Worldwide phylogeography of the citrus brown spot pathogen, Alternaria alternata. Phytopathology 92 794-802.

25. Elliot JA (1917) Taxonomic characters of the genera Alternaria and Macrosporium. Am J Bot 4: 439-476.

26. Neergaard P (1945) Danish species of Alternaria and Stemphylium. Taxonomy, parasitism, economical significance. Copenhagen: Einar Munksgaard.

27. Joly P (1964) Le Genre Alternaria. Encyclopedie Mycologique 33: 250

28. Pryor BM, Gilbertson RL (2000) Molecular phylogenetic relationships amongst Alternaria species and related fungi based upon analysis of nuclear ITS and $\mathrm{mt}$ SSU rDNA sequences. Mycol Res 104: 1312-1321.

29. Pryor BM, Bigelow DM (2003) Molecular characterization of Embellisia and Nimbya species and their relationship to Alternaria, Ulocladium and Stemphylium. Mycologia 95: 1141-1154

30. Hong SG, Maccaroni M, Figuli PJ, Pryor BM, Belisario A (2006) Polyphasic classification of Alternaria isolated from hazelnut and walnut fruit in Europe. Mycol Res 110: 1290-1300.

31. Simmons EG (1967) Typification of Alternaria, Stemphylium, and Ulocladium. Mycologia 59: 67-92.

32. Simmons EG (1981) Alternaria theme and variations. Mycotaxon 13: 16-34.

33. Simmons EG (1986) Alternaria themes and variations (22-26). Mycotaxon 25 287-308.

34. Simmons EG (1995) Alternaria themes and variations (112-144). Mycotaxon 54: 55-163.

35. Simmons EG (2002) Alternaria themes and variations (305-309) Lewia/ Alternaria revisited. Mycotaxon 83: 127-145

36. Simmons EG, Roberts RG (1993) Alternaria themes and variations (73) Mycotaxon 48: 109-140.

37. Andersen B, Thrane U (1996) Differentiation of Altemaria infectoria and Alternaria alternata based on morphology, metabolite profiles, and cultura characteristics. Can J Microbiol 42: 685-689.

38. Andersen B, Kroger E, Roberts RG (2001) Chemical and morphological segregation of Alternaria alternata, A. gaisen and A. longipes. Mycol Res 105 291-299.

39. Andersen B, Kroger E, Roberts RG (2002) Chemical and morphological segregation of Alternaria arborescens, A. infectoria and A. tenuissima speciesgroups. Mycol Res 106: 170-182.

40. Andersen B, Frisvad JC (2002) Characterization of Alternaria and Penicillium species from similar substrata based on growth at different temperature, $\mathrm{pH}$ and water activity. Syst Appl Microbiol 25: 162-172.

41. Roberts RG (2005) Alternaria yaliinficiens sp. nov. on Ya Li pear fruit: from interception to identification. Plant Dis 89: 134-145.

42. Stewart JE (2011) Mating system and speciation of the citrus brown spot pathogen, Alternaria alternata. Dissertation, Washington State University, 156.

43. Nishimura S, Kohmoto K (1983) Host-specific toxins and chemical structures from Alternaria species. Ann Rev Phytopathol 21: 87-116.

44. Kakvan N, Zamanizadeh H, Morid B, Taheri H, Hajmansor S (2012) Study on pathogenic and genetic diversity of Alternaria alternata isolated from citrus hybrids of Iran, based on RAPD-PCR technique. Euro J Exp Biol 2: 570-576.

45. Simmons EG (2007) Alternaria an Identification manual. CBS-KNAW fungal biodiversity centre, Netherland, 775

46. Safaie N, Alizadeh A, Saidi A, Rahimian H, Adam G (2005) Molecular characterization and genetic diversity among Iranian populations of Fusarium graminearum, the causal agent of wheat head blight. Iranain Journal of Plant Pathology 41: 69-73 